\title{
AVALIAÇÃO ERGONÔMICA DE UM POSTO DE TRABALHO EM UMA PADARIA/CONFEITARIA NO MUNICÍPIO DE MONTES CLAROS-MG
}

\author{
SANTOS JÚNIOR, Valdevino José dos ${ }^{1}$
}

\begin{abstract}
Recebido em: 2019.12 .03
Aprovado em: 2020.09.22

ISSUE DOI: $10.3738 / 1982.2278 .3723$

RESUMO: O presente estudo teve por objetivo efetuar uma análise ergonômica do trabalho (AET) em um posto de trabalho de uma Padaria/confeitaria no município de Montes Claros-MG, com intuito de identificar os fatores de risco ergonômico dos postos de trabalho. A AET divide-se em etapas e ações, para conhecer a realidade da empresa, permitindo fazer o levantamento das condições de trabalho e identificar os fatores de risco ergonômico que os empregados estão expostos. E permitiu ainda, o direcionamento da pesquisa ao posto de trabalho com maior demanda ergonômica e por fim, realizou-se a análise da tarefa e da atividade no trabalho selecionado. Nos resultados, obteve-se a demanda ergonômica que direcionou o estudo ao Padeiro, devido à exposição a um ambiente com maior nível de risco, e serviu-se de instrumento para a análise da tarefa, que por meio de observações, identificou os maquinários manuseados e as atividades exercidas durante a jornada de trabalho. Com a AET, concluiu-se a necessidade de adaptar o trabalho às particularidades dos empregados, atentando-se à NR-17.
\end{abstract}

Palavras-chave: Ergonomia. NR-17. Padeiro. Panificadora. Fatores de risco ergonômico.

\section{ERGONOMIC EVALUATION OF A WORK POSITION IN A BAKERY / CONFECTIONERY IN THE MUNICIPALITY OF MONTES CLAROS-MG}

\begin{abstract}
SUMMARY: The objective of the present study was to perform an ergonomic analysis of the work (PEA) in a Bakery / confectionery work in the municipality of Montes Claros, MG, in order to identify the ergonomic risk factors of the work stations. The AET is divided into actions and stages, to know the reality of the company, making it possible to survey the working conditions and identify the ergonomic risk factors that the employees are exposed to. It also allowed the research to be directed to the job with greater ergonomic demand and, finally, the task and the activity in the selected work were analyzed. In the results, we obtained the ergonomic demand that directed the study to the Baker, due to the exposure to an environment with a higher level of risk, and served as instrument for the analysis of the task, which through observations, identified the machinery handled and the activities carried out during the working day. With the AET, the need to adapt the work to the particularities of the employees was concluded, considering the NR-17.
\end{abstract}

Keywords: Ergonomic, NR-17, Baker. Bakery. Ergonomic risk factors.

\section{INTRODUÇÃO}

As Padarias/confeitarias atuam no setor secundário da economia, exigindo intenso empenho físico, acompanhadas muitas vezes por condições e ambientes de trabalhos precários, acarretando agravos à saúde e segurança dos trabalhadores (CONCLA, 2010; ROCHA et al., 2011).

\footnotetext{
${ }^{1}$ ORCID iD http://orcid.org/0000-0001-6078-5282. Engenheiro Ambiental e de Segurança do Trabalho. Mestre em Engenharia de Biossistemas (PGEB/UFF). Doutorando em Meio Ambiente (PPGMA/UERJ).
} 
No Brasil é assegurado o direito dos trabalhadores rurais e urbanos, quanto à redução de riscos trabalhistas, por meio de legislação de higiene, saúde e segurança do trabalho (BRASIL,1988). Assim, é dever do empregador garantir um ambiente de trabalho planejado de forma a minimizar riscos à segurança e saúde dos funcionários (ROCHA et al., 2011; SESI, 2005).

O Ministério do Trabalho e Emprego (MTE) em 1978 publicou as Normas Regulamentadoras (NRs), tendo atuação em diferentes áreas. Dentre elas, a NR-17, que dispõe sobre a Ergonomia, estabelecendo diretrizes para a "adaptação das condições de trabalho às características dos trabalhadores, de modo a proporcionar um máximo de conforto, segurança e desempenho eficiente" (ATLAS, 2013).

O termo ergonomia trata-se, para Lima (2003), de uma "ciência que estuda, no sentido amplo, a adaptação do trabalho ao homem”. Para Silva (2008) o significado etimológico de ergonomia é: "o estudo das leis do trabalho" e ainda argumenta que se trata de um estudo científico da relação entre o homem e seus meios, métodos e espaços de trabalho.

A ergonomia exige adaptações nas condições de trabalho, a saber: aspectos relacionados ao mobiliário, ao levantamento, transporte e descarga manual de cargas, aos equipamentos, à organização e às condições de conforto ambiental de postos de trabalho (ATLAS, 2013; CARVALHO et al., 2010; SESI, 2005).

O presente estudo tem por objetivo efetuar uma avaliação ergonômica em um posto de trabalho de uma Padaria/confeitaria no município de Montes Claros-MG, por meio da Avaliação Ergonômica do Trabalho (AET), além de identificar os perigos e riscos ergonômicos dos postos de trabalho.

\section{REVISÃO DE LITERATURA}

O setor de panificação, segundo o Serviço Brasileiro de Apoio às Micro e Pequenas Empresas (SEBRAE, 2017), é um dos seis maiores segmentos industriais do Brasil. O estado de Minas Gerais apresenta um número considerável de padarias ocupando o segundo lugar com 7.100 estabelecimentos, atrás do estado de São Paulo, com 14.040 estabelecimentos (ASSOCIAÇÃO BRASILEIRA DA INDÚSTRIA DE PANIFICAÇÃO E CONFEITARIA ABIP, 2018).

Em 2017, por meio de um programa de acompanhamento de 400 empresas em 19 Estados do Brasil, com diferentes portes e modelos de atuação, o ITPC, estimou um crescimento no setor 
de 3,2\%, sem descontar a inflação, um valor que equivale a um faturamento de 90,3 bilhões de reais (INSTITUTO TECNOLÓGICO DE PANIFICAÇÃO E CONFEITARIA - ITPC, 2017).

Com a expansão da indústria panificadora e a crescente oferta de emprego, é importante salientar que nesse ramo, alguns postos de trabalho exigem que o trabalhador adote posturas inadequadas. Existem várias profissões que exigem dos trabalhadores grandes esforços físicos, em função da necessidade para o carregamento de cargas. Esta situação pode ser agravada se a sobrecarga física for realizada com a adoção de uma postura constrangedora. Em outras palavras pode acarretar o desenvolvimento de patologias músculo-esqueléticas (ORMELEZ; ULBRICHT, 2010).

A ergonomia segundo Daniellou (2004) é uma junção de conhecimentos sobre o ser humano (psicologia, fisiologia, funcionamento cognitivo) e uma prática de ação. Desta forma, entende-se a ergonomia como sendo o estudo científico da relação existente dos trabalhadores e seus métodos, meios e ambientes de trabalho (SOUZA; MAZINI FILHO, 2017). Assim, a ergonomia, segundo a Associação Brasileira de Ergonomia (ABERGO) (2000) atua na modificação dos "sistemas de trabalho para adequar a atividade nele existentes às características, habilidades e limitações das pessoas com vistas ao seu desempenho eficiente, confortável e seguro".

A Ergonomia atua em dois vieses, iniciando-se na redefinição de especificações da aquisição de mobílias e ferramentas de trabalho, até a compreensão dos aspectos mentais da atividade de trabalho das pessoas. Um aspecto importante da Ergonomia é o posto de trabalho, as ferramentas e elementos que devem estar de acordo com as dimensões físicas do ocupante do posto de trabalho, pois, a inadequação antropométrica produz um desequilíbrio postural podendo expor os trabalhadores à: repetições de gestos, posições inadequadas e desconfortáveis, maior esforço despendido, fatores causais das doenças ocupacionais (VIDAL, 2010; ROSA; QUIRINO, 2017).

O termo Análise Ergonômica do Trabalho (AET) era pouco conhecido, conforme Ferreira (2015). A partir dos anos de 1990, o termo passou a ser mais utilizado após a publicação de normas, disciplinando matérias de saúde e segurança do trabalhador brasileiro, competindo aos empregadores realizar a AET, como disposto na NR-17.

A análise ergonômica do trabalho consiste em intervir na área de trabalho, realizando estudos sobre o desenvolvimento e efeitos físicos e psicofisiológicos, decorrentes da atuação humana laboral. Baseia-se em entender a conjuntura do trabalho, contrapor capacidades e restrições nos moldes da ergonomia, identificar situações críticas através da legislação oficial, determinar propostas, modificações e sugestões de adaptações em processos, produtos, postos de trabalho e ambientes laborais (FERREIRA; RIGHI, 2009). 
Segundo Pizo e Menegon (2010) a AET baseia-se na compreensão do trabalho para poder transformá-lo. A AET visa determinar uma relação global entre os problemas oriundos da organização de trabalho e as decorrências de possíveis aparições de lesões físicas e transtornos psicofisiológicos (FERREIRA e RIGHI, 2009).

\section{METODOLOGIA}

\subsection{A empresa}

A Padaria/confeitaria, objeto do estudo de caso, encontra-se situada no município de Montes Claros, a maior cidade do Norte de Minas Gerais. Esta empresa destaca-se por estar próxima a importantes pontos comerciais, fabris e de universidades, os quais requerem grande demanda de seus produtos.

A empresa funciona de segunda a sexta-feira, das $6 \mathrm{~h}$ às $20 \mathrm{~h}$, aos sábados das $6 \mathrm{~h}$ às $19 \mathrm{~h}$ e aos domingos das $6 \mathrm{~h}$ às $11 \mathrm{~h}$.

Atualmente, na empresa, trabalham oito empregados, a contar com as duas proprietárias, que atuam no posto de trabalho: Caixa. Os empregados exercem suas respectivas funções uns em horário corrido e outros em horários intercalados. Os postos de trabalho e as respectivas escalas de horário estão descritos conforme Tabela 01 a seguir:

Tabela 1 - Postos e horários de trabalho.

\begin{tabular}{ll}
\hline \multicolumn{1}{c}{ Posto de trabalho } & \multicolumn{1}{c}{ Horário de trabalho (h) } \\
\hline Ajudante de Padeiro & $10: 30$ às 17:30 \\
\hline Atendente/balconista A & $06: 00$ às 13:00 \\
\hline Atendentes/balconista B & $07: 00$ às 11:00 e de 13:00 as 17:00 \\
\hline Atendentes/balconista C & $13: 00$ às 20:00 \\
\hline Caixa A & $06: 00$ às 13:00 e das 17:00 às 20:00 \\
\hline Caixa B & $13: 00$ às 17:00 \\
\hline Diarista & $07: 00$ às 15:00 (03 vezes por semana) \\
\hline Padeiro & $04: 00$ às 12:00h \\
\hline
\end{tabular}

Fonte: Elaborado pelo autor (2019).

O estudo foi realizado nos meses de janeiro e fevereiro de 2019, totalizando quatro visitas à empresa, com intuito de observar e analisar os postos de trabalho. 
O método utilizado neste estudo foi a Análise Ergonômica do Trabalho (AET), que de acordo com Arruda et al. (2005) permite o conhecimento da relação entre o homem e o ambiente de trabalho, e permite ainda a melhoria da saúde e segurança e da consequente qualidade de vida no trabalho.

A análise ergonômica do trabalho segundo Arruda et al. (2005), Lima (2003) e Souza (2002) é um conjunto de ações e etapas (Figura 1):

Figura 1 - Etapas da AET.

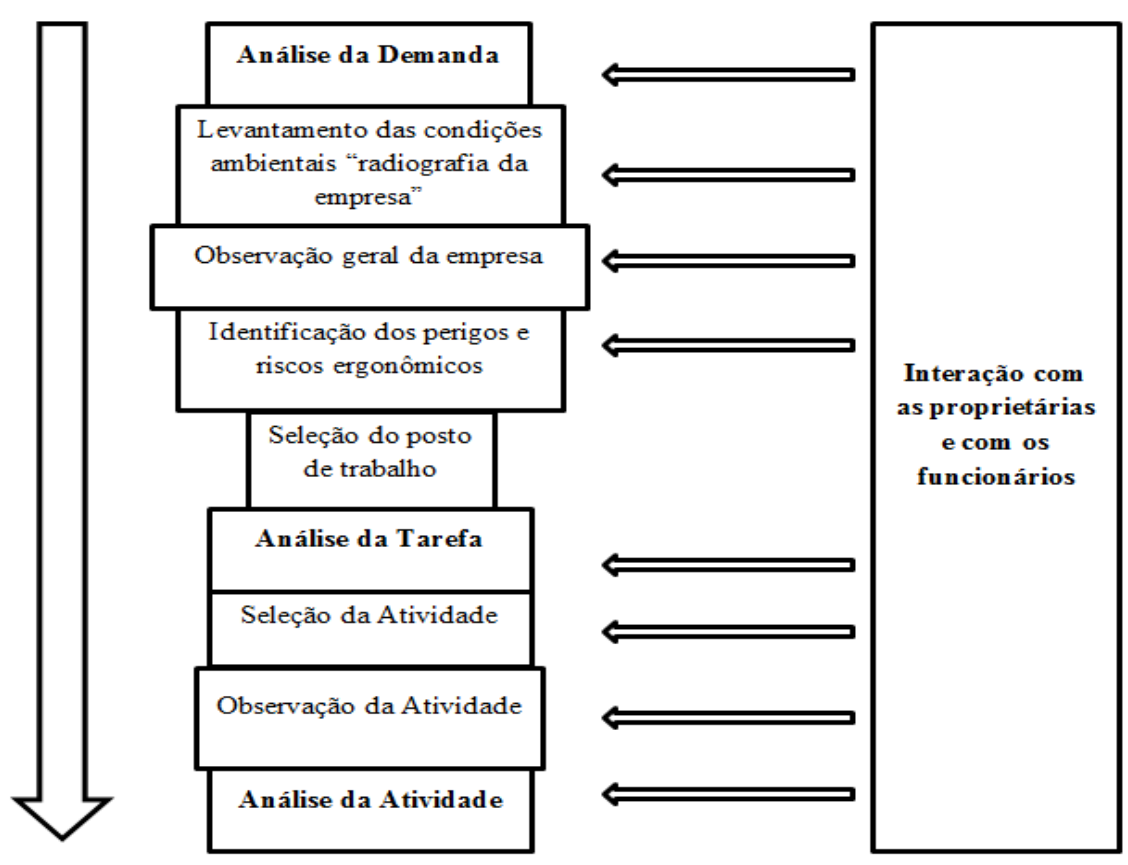

Fonte: Elaborado pelo autor (2019).

A AET subdivide-se em três grandes etapas, sendo elas: Análise da demanda, Análise da tarefa e Análise da atividade, conforme descritas a seguir:

Análise da demanda: é o ponto de partida, é o momento da definição do problema, que é conduzido a partir de hipóteses, de dados concretos fornecidos pelos diferentes atores sociais envolvidos.

Esta etapa foi baseada em questionários e entrevistas elaborados pelos autores, que foram aplicados às proprietárias e a todos os empregados da empresa. Isso possibilitou a identificação de insatisfações e possíveis questões problemáticas relacionados à Ergonomia.

Foram aplicados questionários e entrevistas semiestruturados, com 22 questões, que continham itens como: 1. O perfil do empregado (cargo, idade, sexo, escolaridade, qualificação, admissão, tempo de serviço e horas de trabalho no cargo atual, horas extras, treinamentos); 2. Fatores no ambiente de trabalho (satisfação com o trabalho e com o ambiente, fatores de risco, fornecimento e utilização de EPIs, tempo de descanso e conforto ambiental); 3. Questões 
administrativas (manutenção de máquinas e equipamentos, transporte de cargas e materiais, entre outros); 4. Observação das atividades e tarefas exercidas no posto de trabalho.

Nesta etapa, incluiu-se a identificação dos fatores de risco ergonômicos em todos os postos de trabalho, e selecionando aquele que requer maior demanda ergonômica, servindo-se de instrumento para as próximas fases da AET.

2. Análise da tarefa: após a análise da demanda, foi realizado um levantamento das condições trabalhistas do posto de trabalho selecionado.

3. Análise da atividade: nesta etapa efetuou-se o levantamento e a análise das condições de operação da atividade executadas pelo posto anteriormente selecionado.

O presente estudo pode ser classificado como exploratório-descritivo. É exploratório, pois, com a aplicação de questionários e a realização de entrevistas semiestruturados junto às proprietárias e aos empregados, pode-se conhecer as tarefas e atividades exercidas na padaria, bem como direcionar a pesquisa, elencar os fatores de risco dos empregados e selecionar o posto de trabalho de maior relevância ao estudo. E é descritivo, pois, foi descrita minunciosamente a atividade que demanda maior esforço por parte do empregado demandante.

Por fim, foi realizado o registro fotográfico do ambiente de trabalho e das atividades realizadas no recinto.

\section{RESULTADO E DISCUSSÃO}

\subsection{Análise da demanda}

A demanda ergonômica é o ponto inicial para AET, o que permitiu fazer o levantamento das condições ambientais da Padaria, ou seja, a "radiografia" da empresa.

A empresa pode ser dividida em dois ambientes: o local de vendas, onde há exposição de produtos e a comercialização de mercadorias, no qual podem ser encontrados os postos de trabalho: Atendentes/balconistas e Caixas; e área de produção, local em que se encontram o Padeiro, Ajudante de Padeiro. A Diarista é o único posto de trabalho que atua nos dois ambientes.

As condições dos ambientes encontradas na Padaria/confeitaria estão descritas a seguir:

Ventilação: o local de vendas apresenta boa ventilação natural, devido à presença de duas grandes portas na entrada da Padaria, conta também com um ventilador localizado na parede entre as portas, permitindo uma maior circulação de ar. Na área de produção, a ventilação é um pouco menor em relação ao primeiro local. Há uma janela que contribui para a ventilação natural e o ambiente ainda conta com o auxílio de um ventilador e um exaustor, para melhorar a circulação de ar e a retirada de vapores liberados dos fornos. 
Conforto térmico: no local de vendas, as atendentes/balconistas queixaram-se da temperatura do ambiente em determinadas horas da jornada de trabalho, resposta semelhante, foram aos daqueles que trabalham na área de produção. Eles salientam que quando os formos estão em funcionamento (calor radiante), o ventilador e o exaustor são acionados, mas a temperatura do ambiente pouco se ameniza.

Iluminação: no local de vendas, a iluminação é adequada durante toda a jornada de trabalho para os que trabalham como Atendentes/balconistas e Caixa. Entretanto, para os que trabalham na área de produção, sobretudo no horário entre as $4 \mathrm{~h}$ e $7 \mathrm{~h}$ e das $18 \mathrm{~h}$ às $20 \mathrm{~h}$, a iluminação é de fonte artificial de baixa iluminância não difusa. Segundo A iluminação deve ser ajustada ao tipo de trabalho que está sendo realizado, evitando reflexos e ofuscamentos, cabendo, se necessário, de iluminação complementar ou especial (BRASIL, 2005).

Cores: os dois ambientes possuem paredes, piso e maquinários com cores claras, corroborando para o conforto ambiental dos trabalhadores além de manter as boas condições de higiene do local de trabalho.

Ruído: o nível de ruído na empresa é baixo, as máquinas são novas, tem manutenção sistemática e periódica e são bem lubrificadas. Vasconcelos et al. (2015) na análise de riscos no ambiente de trabalho em duas indústrias de panificação, no processo de produção de biscoitos, identificou na maioria dos processos, níveis de ruídos de $82,2 \mathrm{~dB}(\mathrm{~A})$, estando abaixo do limite de tolerância que é de $85 \mathrm{~dB}(\mathrm{~A})$, sendo classificado como risco tolerável, estando de acordo com a NR-9. Conforme a NR-15, o nível de ruído contínuo ou intermitente é de $85 \mathrm{~dB}(\mathrm{~A})$ para 8 horas diárias. Caso o trabalhador esteja exposto a nível de pressão sonora acima disso, a atividade será classificada como insalubre, incumbindo a empresa adotar medidas de redução de ruídos. Como plano de ação, recomenda-se o uso de protetor auricular com atenuação do nível de ruído em $10 \mathrm{~dB}(\mathrm{~A})$.

Vibração: os trabalhadores estão expostos a baixas vibrações. O equipamento que produz maior vibração é o liquidificador industrial, e este é ligado poucas vezes durante a jornada de trabalho, ou seja, o trabalhador tem pouco tempo de exposição.

Substâncias químicas: excetuando o posto de trabalho Caixa, todos os outros postos manuseiam substâncias químicas. As Atendentes/balconistas e a Diarista têm contato com: água sanitária, detergente, hipoclorito de sódio. O Padeiro e o Ajudante utilizam em algumas massas um pó branco, comumente chamado de "reforçador", para evitar o inchaço excessivo dos pães, além do amido de milho e fermento.

Arranjo físico e mobiliário: a empresa não possui assento adequado ao posto de trabalho Caixa, que se adapte às características do trabalhador. Os assentos devem ter um encosto reto e ajustável, para manter a coluna reta, evitando dores nas costas, e caso a cadeira seja alta, utilizar 
um apoio levemente inclinado nos pés (UNICAMP, 2001). As Atendentes/balconistas exercem esta atividade em pé e andando, e não há local para descanso, que possibilite alternar as posturas executadas com a posição sentada. No artigo 199, do Decreto-lei $n^{\circ} 5.452 / 1943$, que aprovou a Consolidação das Leis do Trabalho (CLT), descreve que é obrigatória a colocação de assentos que assegurem a postura correta ao trabalhador, evitando posturas incômodas ou forçadas, sempre que a execução da tarefa exija que ele trabalhe sentado. E no parágrafo único deste mesmo artigo, está previsto que, quando o trabalho tiver que ser realizado em pé, os trabalhores deverão ter assentos a disposição para serem utilizados durante as pausas quando o serviço permitir (BRASIL, 1943). Para Merola (2017), os trabalhadores deveriam ter um intervalo de 15 minutos, para a jornada de trabalho entre quatro e seis horas; e de pelo menos uma hora, caso a jornada de trabalho for superior a seis horas. O local de vendas possui bom espaço para o trânsito de fregueses, porém o espaço de trabalho do Caixa e das Atendentes/balconistas é insuficiente para a movimentação e a execução de atividades rotineiras. Quanto aos postos de trabalho Padeiro e Ajudante de Padeiro, esses atuam num ambiente com alguns maquinários e mobílias (fornos, batedeira e modelador de pães, freezer, mesas e pia), dificultando a movimentação desses empregados. Alguns maquinários e mobílias, como a amassadeira e bancada, exigem postura inadequada do Padeiro e do Ajudante, sendo necessário adequações a altura do Padeiro e do Ajudante de Padeiro, que têm altura aproximada. Para Brasil (2005) a altura da bancada deverá se ajustar à estatura dos empregados, de modo que, quando esses estiverem em pé, a superfície de trabalho esteja ao nível dos cotovelos. Dessa forma, ele poderá ficar com os ombros relaxados e as costas eretas. A Diarista tem dificuldades na execução de suas tarefas, ora pelo espaço reduzido, ora pela necessidade de mover mobílias e maquinários pesados de um local para o outro para a adequada limpeza dos ambientes.

Organização do trabalho: os empregados têm um local isolado para guardar seus pertences pessoais. As tarefas são repartidas entre os empregados da empresa, como nas atividades exercidas pelo Ajudante de Padeiro e o Padeiro, porém como o Ajudante durante as visitas encontrava-se em processo de aprendizagem, a maior parte das atividades ficava para o Padeiro. Alguns maquinários necessitam ser transferidos de um ponto para outro dentro da área de produção, como por exemplo, a modeladora de pães dificultando a passagem dos empregados nesta área.

Transporte de cargas: o transporte dos sacos de trigo, fécula, caixa de ovos, por exemplo, é realizado por terceiros. No entanto, o Ajudante de Padeiro e o Padeiro transferem estes produtos para baldes, que chegam a pesar cerca de $15 \mathrm{~kg}$, iniciando-se desta forma, a pesagem dos ingredientes. 
Um exemplo prático de levantamento de cargas na indústria da panificação é o transporte manual da farinha, pois, exige um esforço físico por parte de quem realiza esta tarefa. Dependendo também das condições do piso, obstáculos existentes, distância percorrida, frequência e duração desta. O transporte da sacaria deverá respeitar as condições de saúde do trabalhador e seu treinamento para esta tarefa (BRASIL, 2005).

O transporte manual e levantamento de cargas pesadas devem ser realizados por equipamentos mecânicos. Caso isso não seja possível, várias pessoas devem trabalhar em conjunto, utilizando os métodos adequados de levantamento. O levantamento de cargas deve ser realizado com o auxílio das pernas e não das costas. A postura certa é com os ombros para trás, as costas arqueadas e os joelhos dobrados (BRASIL, 2005).

Com os fatores supracitados, realizou-se o levantamento dos perigos e riscos ergonômicos sobre os todos postos de trabalho. Para este fim, considerou-se neste estudo quatro postos de trabalho, atentando-se às peculiaridades dos cargos e funcionários, a citar: altura, sexo e exposição ao mesmo ambiente, ou seja, exposição aos mesmos fatores de risco ergonômicos.

A Tabela 02 abaixo estão elencados os fatores de risco nos quatro postos de trabalho identificados na padaria/confeitaria:

Tabela 02 - Perigos e riscos sobre os postos de trabalho na padaria/confeitaria.

(Continua)

$\begin{array}{cccc}\text { POSTO DE } & \text { PERIGOS } & \text { CAUSAS/FONTES } & \text { RISCOS AVALIADOS } \\ \text { TRABALHO } & \text { IDENTIFICADOS } & \end{array}$

1. Ajudante de 1. Exigência de postura $\mathrm{O}$ trabalho é realizado Má circulação, fadiga e inchaço padeiro e padeiro inadequada. somente na posição dos membros inferiores, alteração (Trabalho em pé) em pé. da pressão arterial, lordose, varizes.

2. Movimentos repetitivos, Trabalho manual. exemplo: flexão de cotovelos e ombros, elevação e abdução dos ombros.

\begin{tabular}{lll}
\hline 3. Exposição ao calor & Baixa ventilação \\
(Temperatura ambiente). & elima regional. & $\begin{array}{l}\text { Desidratação, sudorese, cefaleia, } \\
\text { irritação, alteração de humor, } \\
\text { desconforto com a temperatura } \\
\text { ambiente. }\end{array}$ \\
\hline
\end{tabular}

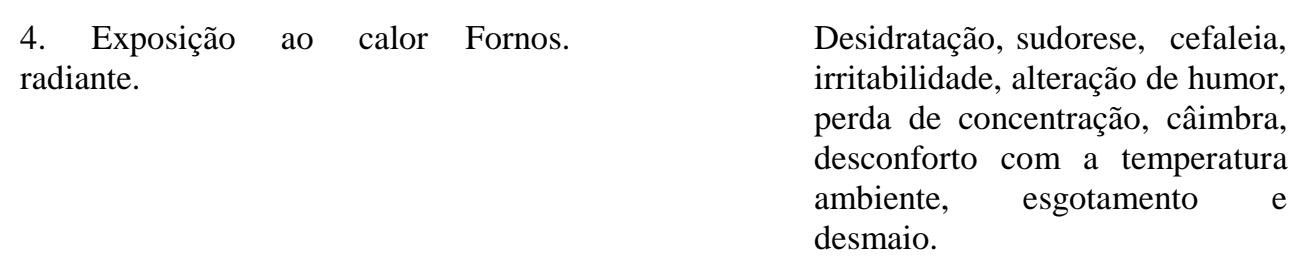

LER/DORT, dores musculares, tendinite.

\begin{tabular}{lll}
\hline $\begin{array}{l}\text { 5. Contato com partes } \\
\text { móveis, eixos girantes. }\end{array}$ & $\begin{array}{l}\text { Pás da amassadeira e } \\
\text { modeladora de pães. }\end{array}$ & $\begin{array}{l}\text { Corte, amputação de membros, } \\
\text { escoriações, fratura, infecções. }\end{array}$ \\
\hline 6. Movimentação excessiva. & $\begin{array}{l}\text { Ritmo intenso de } \\
\text { trabalho. }\end{array}$ & $\begin{array}{l}\text { Fadiga física e respiratória, dores } \\
\text { musculares, câimbra, lordose } \\
\text { lombar. }\end{array}$
\end{tabular}


Tabela 02 - Perigos e riscos sobre os postos de trabalho na padaria/confeitaria.

(Continuação)

$\begin{array}{cccc}\text { POSTO DE } & \text { PERIGOS } & \text { CAUSAS/FONTES } & \text { RISCOS AVALIADOS } \\ \text { TRABALHO } & \text { IDENTIFICADOS } & & \end{array}$

\begin{tabular}{|c|c|c|c|}
\hline \multirow[t]{5}{*}{$\begin{array}{l}\text { 1. Ajudante de } \\
\text { padeiro e padeiro }\end{array}$} & $\begin{array}{l}\text { 7. Levantamento e transporte } \\
\text { de manual de cargas. }\end{array}$ & $\begin{array}{l}\text { Transferência de } \\
\text { matérias-primas para } \\
\text { baldes. }\end{array}$ & $\begin{array}{l}\text { Lordose lombar, fadiga } \\
\text { muscular, luxação, } \\
\text { distensão, fratura. }\end{array}$ \\
\hline & 8. Exposição ao ruído. & $\begin{array}{l}\text { Amassadeira, } \\
\text { liquidificador. }\end{array}$ & $\begin{array}{l}\text { Cefaleia, perda auditiva, } \\
\text { labirintite, dificuldade de } \\
\text { comunicação, irritabilidade, } \\
\text { impotência sexual, estresse. }\end{array}$ \\
\hline & $\begin{array}{l}\text { 9. Exposição à poeira } \\
\text { química e biológica, ex.: de } \\
\text { aditivos e farinha. }\end{array}$ & $\begin{array}{l}\text { Manuseio } \\
\text { matérias-primas. }\end{array}$ & $\begin{array}{l}\text { Alergias, irritação dos } \\
\text { olhos e vias respiratórias e } \\
\text { pneumoconioses. }\end{array}$ \\
\hline & $\begin{array}{l}\text { 10. Exposição à vibração de } \\
\text { membros superiores. }\end{array}$ & $\begin{array}{l}\text { Liquidificador, } \\
\text { amassadeira. }\end{array}$ & $\begin{array}{l}\text { Síndrome de } \\
\text { (dedo branco), tendinite, } \\
\text { lesões musculares, } \\
\text { problemas circulatórios. }\end{array}$ \\
\hline & $\begin{array}{l}\text { 11. Exposição a baixa } \\
\text { iluminação }\end{array}$ & $\begin{array}{l}\text { Lâmpadas com baixa } \\
\text { potência, } \\
\text { distribuída e não } \\
\text { difusa. }\end{array}$ & $\begin{array}{l}\text { Fadiga, problemas de visão } \\
\text { e cefaleias. }\end{array}$ \\
\hline
\end{tabular}

\begin{tabular}{|c|c|c|c|}
\hline $\begin{array}{l}\text { 2. Atendente/ } \\
\text { Balconista }\end{array}$ & $\begin{array}{l}\text { 1. Exigência de postura } \\
\text { inadequada. } \\
\text { (Trabalho em pé) }\end{array}$ & $\begin{array}{l}\text { O trabalho é realizado } \\
\text { somente na posição } \\
\text { em pé. }\end{array}$ & $\begin{array}{l}\text { Má circulação, fadiga e } \\
\text { inchaço dos membros } \\
\text { inferiores, alteração da } \\
\text { pressão arterial, lordose, } \\
\text { varizes. }\end{array}$ \\
\hline
\end{tabular}

2. Exposição ao calor. Baixa ventilação. Desidratação, sudorese, (Temperatura ambiente) Clima regional. cefaleia, irritação, alteração de humor, desconforto com a temperatura ambiente.

\begin{tabular}{ll}
\hline 3. Movimentos repetitivos, Trabalho manual. & $\begin{array}{l}\text { LER/DORT, } \\
\text { musculares, tendinite. }\end{array}$ \\
exemplo: flexão de \\
$\begin{array}{l}\text { cotovelos e ombros, } \\
\text { elevação e abdução dos } \\
\text { ombros. }\end{array}$
\end{tabular}

\begin{tabular}{ll}
\hline $\begin{array}{l}\text { 4. Contato com partes Fatiador de frios. } \\
\text { móveis, eixos girantes. }\end{array}$ & $\begin{array}{l}\text { Cortes, amputação de } \\
\text { membros, escoriações, } \\
\text { fratura, infecções. }\end{array}$ \\
\end{tabular}

\begin{tabular}{|c|c|c|}
\hline $\begin{array}{l}\text { 5. Contato com produtos } \\
\text { químicos. }\end{array}$ & $\begin{array}{l}\text { Manuseio de produtos } \\
\text { de limpeza. }\end{array}$ & $\begin{array}{l}\text { Dermatites, intoxicação, } \\
\text { queimaduras, irritação dos } \\
\text { olhos e vias respiratórias. }\end{array}$ \\
\hline
\end{tabular}

\begin{tabular}{|c|c|c|c|c|}
\hline 3. Caixa & $\begin{array}{l}\text { 1. Exigência de } \\
\text { inadequada. } \\
\text { (Trabalho na } \\
\text { sentado) }\end{array}$ & $\begin{array}{l}\text { postura } \\
\text { posição }\end{array}$ & $\begin{array}{l}\text { O trabalho é realizado } \\
\text { na posição } \\
\text { sentado, } \\
\text { sem } \\
\text { adequado. }\end{array}$ & $\begin{array}{l}\text { Sedentarismo, lordose } \\
\text { lombar e cervical, cifose, } \\
\text { estase sanguínea de } \\
\text { membros inferiores. }\end{array}$ \\
\hline
\end{tabular}


Tabela 02 - Perigos e riscos sobre os postos de trabalho na padaria/confeitaria.

(Conclusão)

$\begin{array}{cccc}\text { POSTO DE } & \text { PERIGOS } & \text { CAUSAS/FONTES } & \text { RISCOS AVALIADOS } \\ \text { TRABALHO } & \text { IDENTIFICADOS } & & \end{array}$

\begin{tabular}{|c|c|c|c|}
\hline \multirow[t]{3}{*}{ 3. Caixa } & $\begin{array}{l}\text { 2. Exigência de postura } \\
\text { inadequada. }\end{array}$ & $\begin{array}{l}\text { Mobiliário } \\
\text { inadequado }\end{array}$ & $\begin{array}{l}\text { Dores na coluna, joelho, } \\
\text { lordose, cifose, cansaço. }\end{array}$ \\
\hline & (Agachamento e encurvado) & & \\
\hline & $\begin{array}{l}\text { 3. Movimentos repetitivos, } \\
\text { exemplo: flexão de } \\
\text { cotovelos } \\
\text { elevação e abdução dos } \\
\text { ombros. }\end{array}$ & $\begin{array}{l}\text { Abertura e } \\
\text { fechamento da } \\
\text { máquina registradora. }\end{array}$ & $\begin{array}{l}\text { LER/DORT, dores } \\
\text { musculares, tendinite. }\end{array}$ \\
\hline
\end{tabular}

\begin{tabular}{lll}
\hline 4. Exposição ao calor. & Baixa ventilação. & $\begin{array}{l}\text { Desidratação, sudorese, } \\
\text { cefaleia, irritação, alteração } \\
\text { de humor, desconforto com } \\
\text { (Temperatura ambiente) }\end{array}$ \\
& a temperatura ambiente.
\end{tabular}

\section{Diarista}

1. Exigência de postura inadequada.

(Trabalho em pé)
O trabalho é realizado na posição em pé.

Má circulação, fadiga e inchaço dos membros inferiores, alteração da pressão arterial, lordose, varizes. 2. Exigência de postura
inadequada.

(Agachamento e encurvado)
Limpeza do piso, Dores na coluna, joelho, paredes, mobílias e lordose, cifose, cansaço. equipamentos.

3. Exposição ao calor. Baixa ventilação. Desidratação, sudorese, (Temperatura ambiente) Clima regional. cefaleia, irritação, alteração de humor, desconforto com a temperatura ambiente.

\begin{tabular}{|c|c|c|}
\hline $\begin{array}{l}\text { 4. Movimentos repetitivos, } \\
\text { exemplo: flexão de } \\
\text { cotovelos } \\
\text { elevação e a ombros, } \\
\text { ombros. }\end{array}$ & $\begin{array}{l}\text { Limpeza do piso, } \\
\text { paredes, mobílias e } \\
\text { equipamentos. }\end{array}$ & $\begin{array}{l}\text { LER/DORT, dores } \\
\text { musculares, tendinite. }\end{array}$ \\
\hline
\end{tabular}

5. Movimentação excessiva. Ritmo intenso de Fadiga física e respiratória, trabalho. dores musculares, câimbra, lordose lombar.

\begin{tabular}{|c|c|c|}
\hline $\begin{array}{l}\text { 6. Exposição à poeira } \\
\text { química e biológica, ex.: de } \\
\text { aditivos e farinha. }\end{array}$ & $\begin{array}{l}\text { Limpeza do piso, } \\
\text { paredes, mobílias e } \\
\text { equipamentos. }\end{array}$ & $\begin{array}{l}\text { Alergias, irritação dos } \\
\text { olhos e vias respiratórias, e } \\
\text { pneumoconioses. }\end{array}$ \\
\hline $\begin{array}{l}\text { 7. Contato com produtos } \\
\text { químicos. }\end{array}$ & $\begin{array}{l}\text { Manuseio de produtos } \\
\text { de limpeza. }\end{array}$ & $\begin{array}{l}\text { Dermatites, intoxicação, } \\
\text { queimaduras, irritação dos } \\
\text { olhos e vias respiratórias. }\end{array}$ \\
\hline $\begin{array}{l}8 . \quad \text { Contato } \\
\text { microorganismos. }\end{array}$ & $\begin{array}{l}\text { Limpeza de banheiro } \\
\text { e piso. }\end{array}$ & $\begin{array}{l}\text { Dermatites, doenças } \\
\text { infectocontagiosas. }\end{array}$ \\
\hline
\end{tabular}

Fonte: Elaborado pelo autor (2019). 
Após a análise da demanda e da identificação dos perigos e riscos, passou-se para a segunda etapa da AET.

\subsection{Análise da tarefa}

Em função das condições ambientais da empresa anteriormente apresentadas e a análise de riscos dos postos de trabalho demonstrados na Tabela 01 (na primeira etapa), o posto de trabalho que requereu maior demanda ergonômica foi o que engloba o Ajudante de Padeiro e o Padeiro. Apesar de estarem situados basicamente sob as mesmas condições ambientais e de perigos e riscos ergonômicos, foi selecionado o Padeiro pelos seguintes motivos: estar empregado há mais tempo neste cargo, trabalhar em horário corrido (sem intervalo), fazer hora extra, ser o responsável pela maior parte das atividades, ter uma maior jornada de trabalho diário, iniciando às $4 \mathrm{~h}$ e prosseguindo até $12 \mathrm{~h}$, seis vezes por semana.

O posto de trabalho selecionado requer que o funcionário trabalhe na posição em pé durante toda a jornada de trabalho, além do excessivo deslocamento e movimentação na área de produção.

Os maquinários encontrados na área de produção foram substituídos por máquinas com maior capacidade, encontrando-se desta forma em bom estado de conservação e passam regularmente por manutenção. É importante destacar o tempo de uso de alguns maquinários como o cilindro de massa com três anos, a amassadeira tem oito meses e quanto aos fornos, um deles tem cinco anos outro forno com apenas quatro meses de uso. Todos os equipamentos possuem dispositivos de segurança.

Após a esta etapa, de identificação e seleção do posto de trabalho que mais exige do esforço por parte do funcionário, no caso o Padeiro, consegue-se para a terceira etapa.

\subsection{Análise da atividade}

Nesta terceira etapa da AET, que visa realizar o levantamento e analisar as condições de operação da atividade executada pelo posto de trabalho do Padeiro (selecionado na etapa anterior).

O Padeiro exerce diversas atividades na padaria/confeitaria, atuando na produção de pães, bolos e biscoitos. Dentre estas atividades por ele exercidas, foi selecionada a confecção do pão sovado. Esse processo interessa para a proposta deste artigo, pois exige do trabalhador grande esforço físico e a exposição a um ambiente intrínseco, descrito anteriormente, o que pode acarretar consequências à saúde do padeiro. 
A produção do pão sovado tem diversas etapas (Figura 2). O padeiro inicia a confecção medindo os ingredientes (farinha de trigo, ovos, açúcar, sal, fermento e reforçador) em recipientes plásticos, depois colocados em um balde de $15 \mathrm{~kg}$ e em seguida os ingredientes são colocados na amassadeira. Nessa máquina adiciona-se água na massa (Figura 02-A) para obter-se uma mistura homogênea.

Figura 02 - Etapas da atividade de produção do pão sovado.

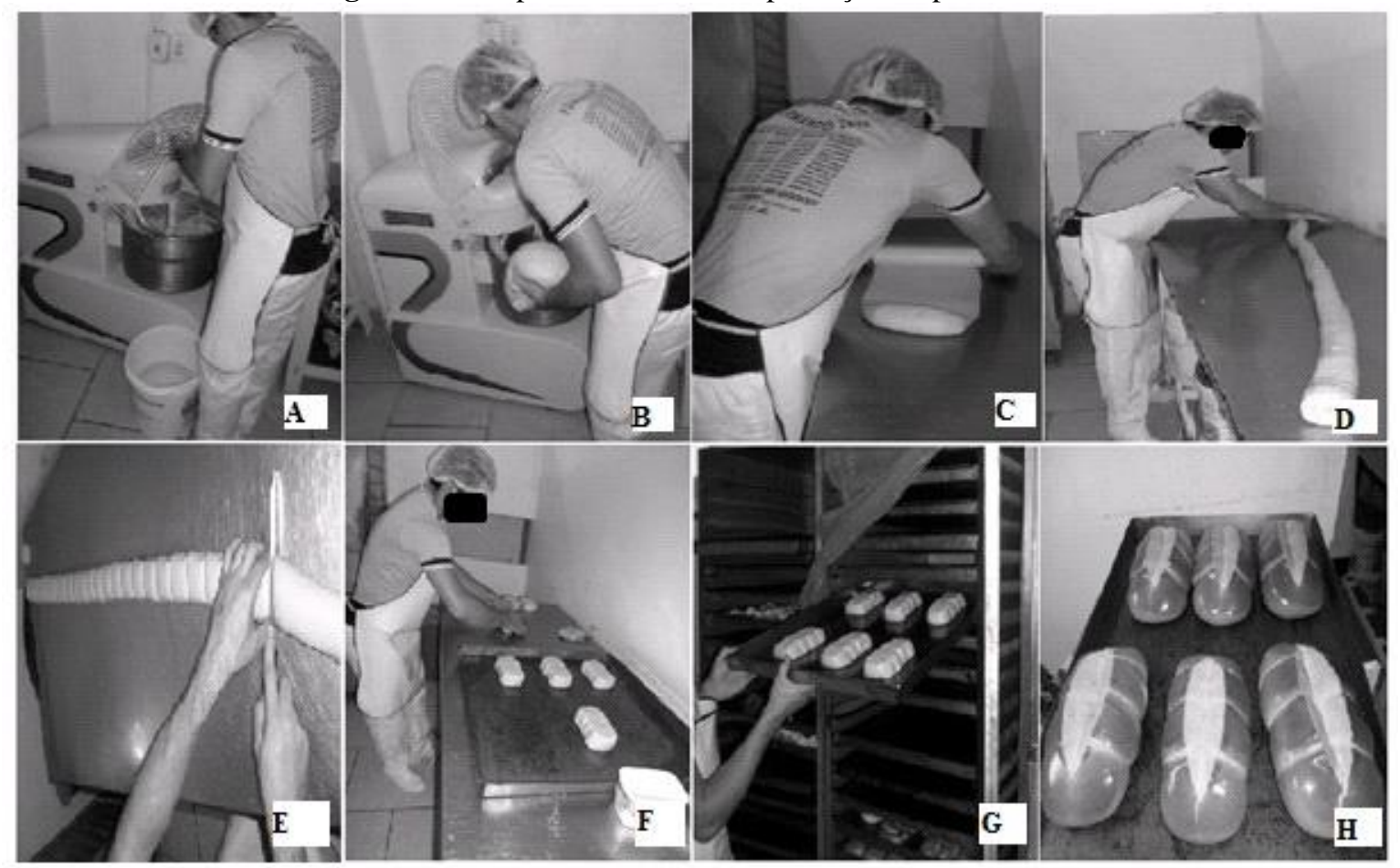

Fonte: Elaborado pelo autor (2019).

A) adição de água na máquina; B) retirada de porções da massa; C) abertura da massa com um rolo; D) modelagem da massa; E) corte da massa em cubos; F) formando o pão sovado; G) armário de fermentação; H) pães sovados assados.

Da nova mistura, são retiradas porções da massa (Figura 02-B) e estas são dispostas em uma mesa de metal untada com óleo, onde começa a abertura da massa com um rolo (Figura 02C). A partir deste momento, é iniciado o processo de modelagem (Figura 02-D) e corte da massa cubos (Figura 02-E), estes são agrupados, dando formato ao pão sovado e depois disposto em formas (Figura 02-F) e lavados para o armário de fermentação (Figura 02-G).

Após um tempo de descanso, o pão cru é retido do armário de fermentação, recebem pinceladas com gemas de ovos e são levados ao forno. Depois de assados (Figura 02-H), os pães são embalados e colocados à venda. 


\section{RECOMENDAÇÕES}

Por meio das observações realizadas no ambiente de trabalho, da identificação dos riscos ergonômicos e da Análise Ergonômica do Trabalho, pode-se detectar problemas e propor sugestões de melhoria aos postos de trabalho. Cabe aqui ressaltar que a implementação de mudanças, depende das proprietárias da empresa. As recomendações foram feitas para o local de vendas e para a área de produção, como apresentada na sequência:

- Ventilação, temperatura e conforto térmico: aumentar o número de ventiladores no local de venda. Na área de produção, instalar mais exaustores;

- Melhorar a iluminação geral na área de produção, devendo ser uniformemente distribuída e difusa, conforme o item 17.5.3.1 da NR-17 e respeitar os valores mínimos estabelecidos pela norma brasileira - NBR 5413;

- Aumentar o número de tomadas na área de produção, para evitar que os cabos dos maquinários fiquem suspensos atrapalhando ou até mesmo impedindo a passagem de empregados.

- Incluir pausa para descanso ou alimentação, de no mínimo uma hora, caso a jornada de trabalho exceda seis horas;

- Adequar a cadeira ao posto de trabalho Caixa;

- Adequar a mesa à altura do Padeiro e do Ajudante de Padeiro (ambos têm altura aproximada);

- Disponibilizar maior quantidade de EPIs (bota, luvas, protetor respiratório) e aumentar a exigência para o uso desses equipamentos;

- Realizar treinamentos, para o uso de EPIs, questões posturais no trabalho, e manuseio de máquinas e equipamentos;

- Propor aos funcionários alongamentos antes, no meio e após a jornada de trabalho, para evitar a fadiga muscular, sobretudo o Padeiro;

- Sugere-se ao Padeiro que durante a utilização da Amassadeira, não colocar a mão dentro do maquinário quando em funcionamento;

- Fixar cartazes de sinalização para o uso de EPIs no ambiente de trabalho;

- Propor uma melhor organização do trabalho junto aos empregados, evitando a disposição de materiais na área de produção e na ampliação do local de circulação das Atendentes/balconistas; 
- Propor melhor divisão de tarefas, para diminuir o número de horas extras realizadas pelo Padeiro.

\section{CONCLUSÃO}

Com este estudo, foi possível efetuar a avaliação ergonômica de um posto de trabalho em uma Padaria/confeitaria no município de Montes Claros-MG, utilizando o método da Análise Ergonômica do Trabalho (AET).

A AET dividiu-se em 03 etapas. Análise da demanda: utilizou-se a observação geral, questionários e entrevistas para a "radiografia" da empresa, e permitiu a descrição dos ambientes e postos de trabalho, a identificação os perigos e risco ergonômicos que os empregados estão expostos; com isso foi selecionado o posto de trabalho Padeiro por requerer maior demanda ergonômica que os outros postos de trabalho.

A análise da tarefa: atentou-se ao posto de trabalho selecionado, por exigir deste profissional excessivas horas de trabalho em pé, com grande movimentação, esforço repetitivo dos membros superiores e exposição a um ambiente com perigos e risco ergonômicos.

A análise da atividade visou à produção do pão sovado por exigir deste trabalhador esforços antiergonômicos.

Conclui-se que na empresa, há exigência de grande esforço dos profissionais que nela atuam, sobretudo do Padeiro. A AET permitiu diagnosticar e fazer algumas recomendações para adaptar as condições de trabalho às particularidades dos funcionários, conforme a NR-17. E para um futuro trabalho, propõe-se a análise, o tratamento e o gerenciamento dos riscos diagnosticados por este estudo.

\section{REFERÊNCIAS}

ASSOCIAÇÃO BRASILEIRA DA INDÚSTRIA DE PANIFICAÇÃO E CONFEITARIA ABIP. Número de padarias por estado 2018. Disponível em:

<https://www.abip.org.br/site/numero-de-padarias-por-estado-2018/>. Acesso em: 27 mar. 2020.

ASSOCIAÇÃO BRASILEIRA DE ERGONOMIA - ABERGO. A certificação do ergonomista brasileiro. Editorial do Boletim, 1, 2000.

ARRUDA et al. Aplicação da análise ergonômica do trabalho (AET) na avaliação do setor padaria em um supermercado em Viçosa/MG. II Workshop de Análise Ergonômica do Trabalho na UFV. Viçosa, 2005.

ATLAS. Segurança e medicina do trabalho. 72 ed. São Paulo: Atlas, 2013.

BRASIL. Constituição da República Federativa do Brasil. Brasília: Senado Federal, 1988. 
BRASIL. Decreto-lei $n^{\circ} 5.452$, de $1^{\circ}$ de maio de 1943. Aprova a Consolidação das Leis do Trabalho. Disponível em: <http://www.planalto.gov.br/ccivil_03/decreto-lei/del5452.htm>. Acesso em: 28 mar. 2020.

BRASIL. Dicas de Prevenção de Acidentes e Doenças no Trabalho. SESI - SEBRAE. Brasília: SESI-DN, 2005.

CARVALHO et al. Avaliação ergonômica das condições de trabalho em pequenas padarias de uma cidade do interior Minas Gerais. Revista EPeQFafibe. 2 ed., v. 01, 27-32, 2010.

COMISSÃO NACIONAL DE CLASSIFICAÇÃO - CONCLA. Resolução 02/2010. CNAE Alterações na Denominação de Códigos, Inclusões e Exclusões de Subclasses. Disponivel em: <http://www.abip.org.br/imagens/file/Resolu\%C3\%A7ao_CONCLA_02_10_-_CNAE__Altera\%C3\%A7oes_na_Denomina\%C3\%A7ao_de_C\%C3\%B3digos,_Inclusoes_e_Exclusoes_ de_Subclasses_-_Divulga\%C3\%A7ao.pdf >. Acesso em: 24 jan. 2019.

DANIELLOU, F. A ergonomia em busca de seus princípios: debates epistemológicos. São Paulo: Edgard Blücher, 2004.

FERREIRA, L. L. Sobre a Análise Ergonômica do Trabalho ou AET. Rev. bras. Saúde Ocup., São Paulo, v. 40, n. 131, 2015.

FERREIRA, M. D.; RIGHI, C. A. R. Análise ergonômica do trabalho. Ergonomia. 2010. Disponível em: <http://www.luzimarteixeira.com.br/wp-content/uploads/2010/07/analiseergonomica-do-trabalho.pdf>. Acesso em: 15 fev.2019.

INSTITUTO TECNOLÓGICO DE PANIFICAÇÃO E CONFEITARIA - ITPC. Projeção de desempenho das panificadoras e confeitarias brasileiras em 2017. Disponível em :< www.http://institutoitpc.org.br/indicadores-do-setor/ >. Acesso em 02 dez. 2019.

LIMA, J. A de A. Metodologia de análise ergonômica. 73 f. Monografia (Especialização em Engenharia de Produção). Departamento de Engenharia de Produção/CT. UFPB. João Pessoa. 2003.

MEROLA, S. Quanto tempo o trabalhador pode trabalhar de pé, sem tirar pausa para descansar?. 2017. Disponível em:

$<$ https://sergiomerola85.jusbrasil.com.br/artigos/477016388/quanto-tempo-o-trabalhador-podetrabalhar-de-pe-sem-tirar-pausa-para-descansar>. Acesso em 28 mar. 2020.

ORMELEZ, C. R. ; ULBRICHT, L. Análise ergonômica do trabalho aplicada a um posto de trabalhado com sobrecarga física. Revista Uniandrade, v. 11, n. 2, 2010.

PIZO, C. A. ; MENEGON, N. L. Análise ergonômica do trabalho e o reconhecimento científico do conhecimento gerado. Produção, v. 20, n. 4, 657-668, 2010.

ROSA, Mislene; QUIRINO, Raquel. Relações de gênero e ergonomia: abordagem do trabalho da mulher operária. HOLOS, [S.1.], v. 5, p. 345-359, nov. 2017. ISSN 1807-1600. Disponível em: <http://www2.ifrn.edu.br/ojs/index.php/HOLOS/article/view/4772>. Acesso em: 22 mar. 2020. doi: https://doi.org/10.15628/holos.2017.4772. 
ROCHA et al. Riscos do trabalhador na indústria de panificação: estudo de caso em uma panificadora de Natal-RN. 2011. Anais... Belo Horizonte, 2011.

SERVIÇO DE APOIO ÀS MICRO E PEQUENAS EMPRESAS BAHIA - SEBRAE. Indústria: Panificação. Estudo de Mercado, 2017.

SERVIÇO SOCIAL DA INDÚSTRIA - SESI. Manual de Segurança e Saúde no trabalho: Indústria da Panificação. 2005. (Coleção manuais, Sesi).

SILVA, A. A. A ergonomia e o ambiente de trabalho: reflexões sobre as contribuições ergonômicas em bibliotecas. Inf. ; Soc, v. 18, n. 3, 2008.

SOUZA, A. M. P. A. de. A influência das condições de trabalho na atividade de cárie dental de trabalhadores em padaria e confeitarias: estudo de caso. 124 f. Dissertação (Programa de pós-graduação em Engenharia de Produção), Universidade Federal de Santa Catarina, Florianópolis, 2002.

SOUZA, J. A. C. de; MAZINI FILHO, M. L. Análise ergonômica dos movimentos e posturas dos operadores de checkout em um supermercado localizado na cidade de Cataguases, Minas Gerais.

Gest. Prod. v. 24, n. 1, 2017.

UNIVERSIDADE ESTADUAL DE CAMPINAS - UNICAMP. Manual sobre ergonomia. 2001. Disponível em:

<http://www.dgrh.unicamp.br/documentos/manuais/man_dsso_ergonomia.pdf>. Acesso em: 27 mar. 2020.

VASCONCELOS, F. M. de; MAIA, L. R. ALMEIDA NETO, J. A de; RODRIGUES, L. B. Riscos no ambiente de trabalho no setor de panificação: um estudo de caso em duas indústrias de biscoitos. Gest. Prod., v. 22, n. 3, 2015.

VIDAL, M. C. Introdução à ergonomia. Apostila do Curso de Especialização em Ergonomia Contemporânea/CESERG. Rio de Janeiro: COPPE/GENTE/UFRJ, 2010. 